\title{
A subset of microRNAs potentially acts as a convergent hub for upstream transcription factors in cancer cells
}

\author{
HIROAKI OHDAIRA, TOMOE SASAKI and KENICHI YOSHIDA \\ Department of Life Sciences, Faculty of Agriculture, Meiji University, \\ 1-1-1 Higashimita, Tama-ku, Kawasaki, Kanagawa 214-8571, Japan
}

Received June 11, 2010; Accepted July 25, 2010

DOI: 10.3892/or_00000995

\begin{abstract}
RNAs (miRNAs) are non-coding short nucleotides that exhibit a unique function as translational suppressors towards a wide realm of mRNAs. To date, a specific set of miRNAs has been characterized as oncogenes and tumor suppressors based on their expression levels and/or target mRNA functions; however, a comprehensive view of the changes in miRNA expression regulated by pivotal cellular signaling mechanisms remains elusive. Here, we aimed to characterize common and unique miRNAs regulated by transcriptional regulators such as oncogenic HRAS, c-Jun and E2F family members (E2F1 E2F6) in the human cancer cell lines A549 and HeLa. For this purpose, we employed a miRNA microarray and identified several miRNAs that were commonly regulated by transcriptional regulators. Next we tested whether these miRNAs could affect any of the signal pathways by employing luciferase reporters bearing response elements for various cellular signaling pathways. Among those tested, luciferase reporter bearing interferon $\gamma$ activation site responsive element was solely activated by $m i R-494$, indicating that the overexpression of $m i R-494$ has a limited effect on a specific signal pathway in A549 cells. Taken together, these results suggest that a unique subset of miRNAs could have an integrating effect on upstream pivotal transcriptional regulators influencing decisions regarding proper cellular responses.
\end{abstract}

\section{Introduction}

The mechanics of cancer biology have been extensively investigated leading to the realization that complex behaviors

Correspondence to: Dr Kenichi Yoshida, Department of Life Sciences, Faculty of Agriculture, Meiji University, 1-1-1 Higashimita, Tama-ku, Kawasaki, Kanagawa 214-8571, Japan

E-mail: yoshida@isc.meiji.ac.jp

Abbreviations: GAPDH, glyceraldehyde-3-phosphate dehydrogenase; GAS, interferon $\gamma$ activation site; MAP, mitogen-activated protein; miRNA, microRNA; PCR, polymerase chain reaction; $\mathrm{pRb}$, retinoblastoma protein; RT, reverse transcription; UTR, untranslated region

Key words: microRNA, expression analysis, transcription factor, E2F, c-Jun, RAS involving deregulated oncogenes and the functional loss of tumor suppressors are involved. Genes involved in the regulation of signal transduction pathways and transcriptional regulations are recognized as being the most important targets for investigating cancer biology. So far, factors upstream and downstream of mitogen-activated protein (MAP) kinase cascades has been a central issue (1). RAS is known as a representative upstream regulator of MAP kinase (2). As major downstream regulators or effectors of MAP kinase, transcription factors such as p53 (3), c-Myc (4), c-Jun (5) and retinoblastoma protein (pRb)/E2F (6) are widely recognized, as their proper regulation could be applied to cancer therapy.

Towards a better understanding of the complex molecular networks that are perturbed by deregulated regulators in tumor specimens, numerous target mRNAs controlled by such regulators have been investigated. Besides mRNAs, the importance of microRNAs (miRNAs) in human disease, especially carcinogenesis, has emerged as another important issue (7). At present, more than a dozen miRNAs have been characterized as oncogenes and tumor suppressors $(8,9)$. As a representative tumor suppressive miRNA, let-7 has been shown to inhibit cell proliferation pathways including RAS $(10,11)$. Another tumor suppressor, $m i R-145$, is a p53 target miRNA that directly targets c-Myc for down-regulation (12). Among the known transcriptional regulators of miRNAs, p53-regulated miRNAs have been investigated intensively $(13,14)$. The $m i R-34$ family $(a \sim c)$ has been recognized as tumor suppressors under the control of p53 $(15,16)$. Interestingly, $m i R-34 a$ overexpression resulted in the downregulation of the E2F pathway and the up-regulation of the p53 pathway (17), suggesting a possible regulatory pathway between $\mathrm{p} 53$ and E2F via miRNAs. E2F1 has been implicated in the transcriptional regulation of $m i R-106 b / 93 / 25$ polycistron in a p53-dependent manner (18). Moreover, $m i R-449 a / b$ has been shown to act as a direct target of E2F1. In turn, $m i R$ $449 a / b$ inhibits oncogenic cyclin-dependent kinase 6 (CDK6) and $\mathrm{CDC} 25 \mathrm{~A}$, resulting in $\mathrm{pRb}$ dephosphorylation and thus constituting a negative feedback loop towards the $\mathrm{pRb} / \mathrm{E} 2 \mathrm{~F} 1$ pathway (19). On the other hand, the miR-17-92 oncogene cluster, which is comprised of $m i R-17-5 p$ and $m i R-20 a$, has been shown to be regulated by c-Myc. These miRNAs inhibit the E2F1 activity $(20,21)$. E2F1, the translation of E2F2 and $\mathrm{E} 2 \mathrm{~F} 3$, has also been proven to be suppressed by $m i R-20 \mathrm{a}$, and E2F1 E2F3 were capable of binding to the promoter of $m i R-17-92$ cluster $(22,23)$. Transcription from the $m i R-17-92$ 
cluster has shown to be repressed by p53 under hypoxic conditions (24).

Oncogenic and anti-oncogenic signaling stemming from p53, c-Myc and E2F1 are integrated by specific miRNA species, thus establishing positive and negative feedback regulation (25-28). Accumulating evidence indicates that miRNA expression patterns produced by an miRNA microarray analyses can be applied to cancer diagnosis because the miRNA expression pattern is strongly correlated with the cancer stage and cancer cell type $(29,30)$.

Here, we focused on the profiling of miRNAs that are regulated by pivotal transcriptional regulators in the human cancer cell lines A549 and HeLa. As p53 and c-Myc target miRNAs have been widely reported (31), we selected c-Jun and E2F family members E2F1 E2F6 and their upstream regulator oncogenic HRAS. Although the miR-155 promoter is known to be regulated by activator protein 1 (AP1) containing c-Jun as a heterodimeric protein (32), c-Jundependent regulation of miRNAs is not fully understood. In addition, the differential miRNA transcriptional regulation by E2F family members is still unclear. Our studies illuminate that the mechanism underlying the transcriptional switch regulated by pivotal transcription factors could be integrated into a specific subset of miRNAs in a cell-type specific manner.

\section{Materials and methods}

Cells, RNAs and plasmids. A549 (human lung cancer cells) and HeLa (human cervical cancer cells) were cultured in Earle's modified Eagle's medium (MEM) supplemented with $1 \%$ non-essential amino acids, antibiotic-antimycotics (all from Invitrogen, Carlsbad, CA), and 10\% fetal bovine serum (FBS). Hereafter complete medium is referred to as MEM.

miScript miRNA Mimic (Syn-hsa-miR-483-5p and Syn$h s a-m i R-494)$ and miScript miRNA Inhibitor (anti-hsa-miR139-3p) were purchased from Qiagen (Valencia, CA) as synthesized, double-stranded RNA. The sequences were as follows: Syn- $h s a-m i R-483-5 p$, AAGACGGGAGGAAAGAA GGGAG (Cat. no. MSY0004761); Syn- $h s a-m i R-494$, UGA AACAUACACGGGAAACCUC (Cat. no. MSY0002816), and anti-hsa-miR-139-3p, GGAGACGCGGCCCUGUUGG AGU (Cat. no. MIN0004552). The Sanger miRBase accession numbers for the stem-loop sequences were MI0002467 (official symbol MIR483; hsa-mir-483) and MI0003134 (official symbol MIR494; hsa-mir-494), while those for the mature sequences were MIMAT0004761 (hsa-miR-483-5p) and MIMAT0002816 (hsa-miR-494). The Stealth RNA interference Negative Control Duplexes (High GC Duplex) was purchased from Invitrogen and used as a control.

To construct the pGL3-Promoter (Promega, Madison, WI) reporter using a miRNA target site in the $3^{\prime}$ untranslated region (3'UTR) of the luciferase gene, the following sense and antisense sequences were synthesized and annealed: pGL3-Promoter-483-5p, GCTCTAGAGAATTCCTCCCTTC TTTCCTCCCGTCTTTCTAGAGC and GCTCTAGAAAG ACGGGAGGAAAGAAGGGAGGAATTCTCTAGAGC; and pGL3-Promoter-494, GCTCTAGAGAATTCGAGGTTT CCCGTGTATGTTTCATCTAGAGC and GCTCTAGATG AAACATACACGGGAAACCTCGAATTCTCTAGAGC
(XbaI sites are underlined and EcoRI sites are italicized). Annealed oligonucleotides were digested with $X b a \mathrm{I}$ and inserted into the $X b a I$ site of the pGL3-Promoter. EcoRI digestion to check the existence of the inserted fragments and sequencing with the RV4 primer were performed. The expression vectors encoding HRAS (V12), c-Jun and E2F1 E2F6 were previously described (33-35). pcDNA3 was purchased from Invitrogen.

Transfection and luciferase reporter assay. Cells were transfected with Lipofectamine Plus transfection reagent (Invitrogen) according to the manufacturer's instruction. Briefly, $3 \times 10^{5}$ cells were inoculated into a 6 -well plate the day before transfection. Plasmid DNA (0.5-2 $\mu \mathrm{g}$ per well) mixed with transfection reagent was directly added to the cell cultures. After $48 \mathrm{~h}$ of transfection, the total RNA and cell lysates were recovered for microarray and Western blotting, respectively.

For miRNAs, transfection was performed using the HiPerFect transfection reagent (Qiagen), according to the manufacturer's instructions. The cells were plated into a 24-well dish $24 \mathrm{~h}$ prior to transfection $\left(3 \times 10^{4}\right.$ cells/well). Briefly, 12 pmol $(0.6 \mu \mathrm{l}$ of $20 \mu \mathrm{M}$ stock) RNA and $3 \mu \mathrm{l}$ of transfection reagent were incubated in $100 \mu 1$ of MEM without FBS for $10 \mathrm{~min}$ to facilitate complex formation at room temperature. The resulting mixture was added to the cells cultured in $500 \mu \mathrm{l}$ of MEM. After $24 \mathrm{~h}$, pGL3-Promoter-based luciferase reporters (400 ng) or pTA-Luc (bearing response elements for E2F, Myc, p53, pRb, NFAT, STAT3, ISRE and GAS)/pTAL-Luc (bearing response elements for AP1, CRE, GRE, HSE, NF- $\kappa \mathrm{B}$ and SRE) reporter series (all purchased from Clontech) (200 ng) were transfected with FuGENE6 transfection reagent (Roche, Basel, Switzerland), in accordance with the manufacturer's instructions. Briefly, firefly luciferase reporter plasmid and $0.6 \mathrm{ng}$ of the Renilla luciferase reporter plasmid (pRL-TK; Promega) per 24-well dish were used for each transfection. The cells were lysed at $24 \mathrm{~h}$ after transfection by applying $100 \mu 1$ of Passive Lysis Buffer from the Dual Luciferase Reporter Assay kit (Promega) into each well of the 24-well plate. For E2F1 expression vector and pGL3Promoter-based luciferase reporters co-transfection, cells were lysed at $72 \mathrm{~h}$ after transfection. Five microliters of cell lysate was used for the luciferase reporter assay with the same kit according to the manufacturer's protocol. Light intensity was quantified using a GloMax 20/20n Luminometer (Promega). Experiments were performed at least in triplicate. As a control for transfection efficiency, the firefly luciferase activity values were normalized to the Renilla luciferase activity values. Data are presented as the mean values \pm SD (standard deviation). Statistical differences were analyzed using the Student's t-test. A value of $\mathrm{P}<0.05$ ( $\mathrm{n}=3$ ) was considered to indicate a statistically significant difference.

miRNA microarray analysis. After $48 \mathrm{~h}$ of plasmid transfection, total RNA was extracted using TRIzol reagent (Invitrogen), according to the manufacturer's instructions. The integrity of the RNA was checked using electrophoresis (Agilent 2100 Bioanalyzer; Agilent Technologies, Inc., Santa Clara, CA). The procedure for the microarray analysis $(n=1)$ using the human miRNA Microarray kit Ver.2, which covered 


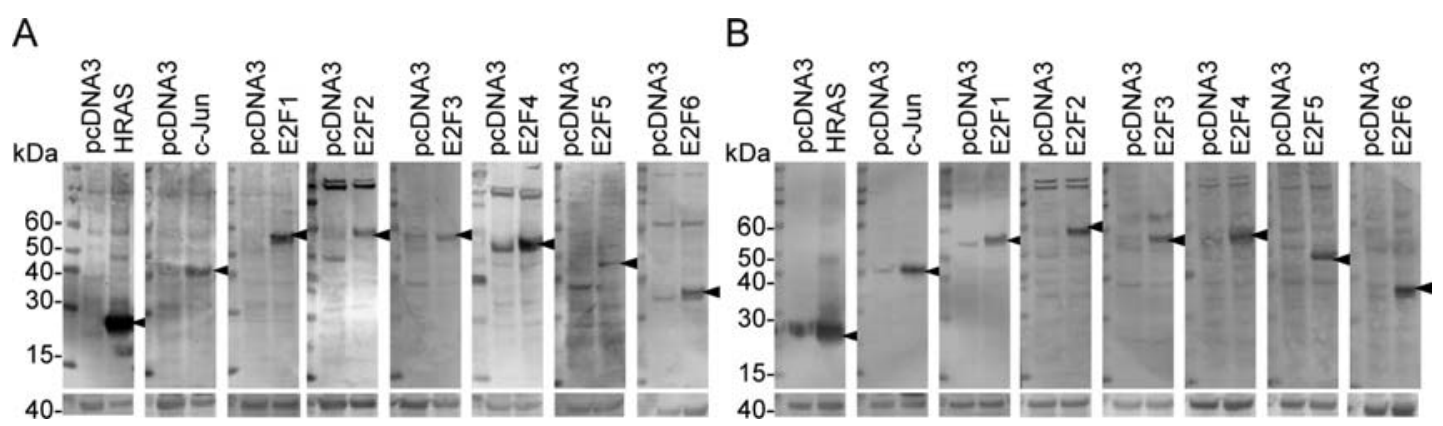

Figure 1. Western blot analysis of indicated protein expressed in A549 (A) and HeLa (B) cells. Arrowhead indicates the position of expressed protein. Molecular weight marker $(\mathrm{kDa})$ is shown on the left side of the panel. Bottom panels are GAPDH loading control.

723 mature and 76 viral miRNAs, was based on the Agilent Technologies protocol (http://www.chem.agilent.com). Briefly, $100 \mathrm{ng}$ of total RNA was dephosphorylated using calf intestine alkaline phosphatase (GE Healthcare, Waukesha, WI), heat-denatured with dimethyl sulfoxide (DMSO) and labeled with T4 RNA ligase (GE Healthcare). After column purification, hybridization and washing were performed using an miRNA Labeling Reagent and Hybridization kit (Agilent) and Gene Expression Wash Pack (Agilent) according to the manufacturer's protocol. Array scanning was performed using a DNA MicroArray Scanner (Agilent). Spot analysis for digitalization of the hybridization images was performed using Feature Extraction Ver.9.5.3 (Agilent) and was compared with the control using GeneSpring GX (Agilent), according to manufacturer's standard manual. Gene expression changes over and under 1.5-fold were extracted and used for further analyses. Signals with present/present for test sample/control were selected for further data analysis. For the miRNA annotation, the authors referred to miRBase (http://www.mirbase.org/) (36).

Western blot analysis. Western blotting was performed using a previously reported method (33). A total of 20-40 $\mu \mathrm{g}$ of cell lysates were used per lane. The following antibodies were used: HRAS (sc-520), E2F1 (sc-193), E2F2 (sc-633), E2F3 (sc-879), E2F4 (sc-866), E2F5 (sc-968) and E2F6 (sc-22823) (all from Santa Cruz Biotechnology, Santa Cruz, CA). Antic-Jun (60A8) was purchased from Cell Signaling Technology (Beverley, MA). Anti-GAPDH was purchased from Applied Biosystems (Foster City, CA).

TaqMan quantitative RT-PCR. RNA (100 ng) was reversetranscribed using specific miRNA stem-loop primers and the TaqMan miRNA reverse transcription kit (Applied Biosystems). Mature miRNA expression was measured with TaqMan microRNA assays (Applied Biosystems) according to the manufacturer's instructions. PCR mixtures included the TaqMan microRNA Assay primer for human miRNAs and TaqMan Universal PCR Master Mix in a total reaction volume of $20 \mu \mathrm{l}$. Reactions were performed with the 9600 emulation (Default) program on a 7500 Fast Real-Time PCR System (Applied Biosystems). Cycling parameters were $95^{\circ} \mathrm{C}$ for $10 \mathrm{~min}$ and then 40 cycles of $95^{\circ} \mathrm{C}$ for $15 \mathrm{sec}$, annealed/ extended at $60^{\circ} \mathrm{C}$ for $1 \mathrm{~min}$. The cycle threshold $(C t)$ values, corresponding to the PCR cycle number at which fluore- scence emission reaches a threshold above baseline emission, were determined, and miRNA expression values were calculated using $R N U 6 B$ as endogenous control (Applied Biosystems) following the comparative $C t(\Delta \Delta C t)$ method. All reactions were performed in triplicate. Results were expressed relative to the control empty vector pcDNA3-transfected cells and arbitrarily assigned a value of 1 .

\section{Results}

Comprehensive analysis of miRNAs regulated by pivotal transcriptional regulators. Identifying and characterizing which miRNAs are regulated by major transcriptional regulators is an intriguing task. As transcriptional regulators, we selected oncogenic HRAS (V12) (37) and c-Jun; activator E2Fs (E2F1 E2F3); and repressor E2Fs (E2F4 E2F6). Expression vectors encoding each cDNA were transiently overexpressed in the widely used cancer cell lines A549 and HeLa. After $48 \mathrm{~h}$ of transfection, the expression level of each protein was detected using Western blotting (Fig. 1). Next, the miRNA signatures were determined using an miRNA microarray, and the up- and down-regulated miRNAs were tabulated (Tables I and II). Significantly, characteristic subsets of miRNAs were coordinately regulated by different transcriptional regulators. As summarized in Fig. 2A, in A549 cells, miR-483-5p was upregulated by activator E2Fs and $m i R-494$ was up-regulated by HRAS, c-Jun, E2F1, E2F3 and E2F6. Similarly, miR-345 was up-regulated by HRAS, c-Jun, E2F1 and E2F3 but downregulated by E2F5 and E2F6. The $m i R-135 a^{*}$ was also upregulated by HRAS, c-Jun, E2F1 and E2F3. The miR-139-3p was down-regulated by repressor E2Fs. In HeLa cells, as shown in Fig. 2B, a dozen of miRNAs were commonly but intricately regulated by transcriptional regulators. For instance, $m i R-26 b$, let-7a, let-7f and let-7 $g$ were up-regulated by E2F1 and repressor E2Fs and miR-638, miR-940 and $m i R-125 a-3 p$ were down-regulated by E2F1 and repressor E2Fs. Both $m i R-29 b$ and $m i R-221$ were down-regulated by activator E2Fs. On the other hand, an array of miRNAs was exclusively downregulated by repressor E2Fs. Several miRNAs were regulated by at least two transcriptional regulators in A549 and HeLa cells (Fig. 2C). For example, miR-483-5p was up-regulated by E2F2 and E2F3 and $m i R-494$ was up-regulated by c-Jun and E2F3. In contrast, miR-139-3p was exclusively downregulated by repressor E2Fs and $m i R-370$ was downregulated by E2F5 and E2F6. 
Table I. Up- and down-regulation of miRNAs by HRAS, c-Jun and E2F1 E2F6 in A549 cells.

\begin{tabular}{|c|c|}
\hline & Ratio \\
\hline \multicolumn{2}{|c|}{ Up-regulated by HRAS } \\
\hline$m i R-345$ & 2.71 \\
\hline$m i R-1224-5 p$ & 1.86 \\
\hline$m i R-125 a-3 p$ & 1.78 \\
\hline $\operatorname{miR}-135 a^{*}$ & 1.74 \\
\hline$m i R-494$ & 1.53 \\
\hline \multicolumn{2}{|c|}{ Down-regulated by HRAS } \\
\hline$m i R-34 a$ & 0.59 \\
\hline$m i R-105$ & 0.62 \\
\hline \multicolumn{2}{|c|}{ Up-regulated by c-Jun } \\
\hline$m i R-494$ & 2.29 \\
\hline $\operatorname{miR}-345$ & 1.96 \\
\hline $\operatorname{miR}-135 a^{*}$ & 1.87 \\
\hline$m i R-188-5 p$ & 1.60 \\
\hline $\operatorname{miR}-575$ & 1.52 \\
\hline \multicolumn{2}{|c|}{ Down-regulated by c-Jun } \\
\hline$m i R-20 b$ & 0.55 \\
\hline$m i R-29 b$ & 0.58 \\
\hline$m i R-424$ & 0.58 \\
\hline$m i R-19 a$ & 0.59 \\
\hline$m i R-183$ & 0.60 \\
\hline$m i R-324-5 p$ & 0.60 \\
\hline$m i R-20 a$ & 0.62 \\
\hline$m i R-374 a$ & 0.63 \\
\hline$m i R-26 b$ & 0.64 \\
\hline$m i R-30 b$ & 0.64 \\
\hline$m i R-27 a$ & 0.65 \\
\hline let-7f & 0.66 \\
\hline$m i R-15 a$ & 0.66 \\
\hline $\operatorname{miR}-31^{*}$ & 0.66 \\
\hline \multicolumn{2}{|c|}{ Up-regulated by E2F1 } \\
\hline$m i R-483-5 p$ & 12.26 \\
\hline$m i R-494$ & 1.92 \\
\hline $\operatorname{miR}-345$ & 1.71 \\
\hline $\operatorname{miR}-135 a^{*}$ & 1.65 \\
\hline$m i R-1225-5 p$ & 1.50 \\
\hline \multicolumn{2}{|c|}{ Down-regulated by E2F1 } \\
\hline$m i R-183$ & 0.54 \\
\hline$m i R-455-3 p$ & 0.64 \\
\hline \multicolumn{2}{|c|}{ Up-regulated by E2F2 } \\
\hline$m i R-483-5 p$ & 5.92 \\
\hline \multicolumn{2}{|c|}{ Down-regulated by E2F2 } \\
\hline miR-105 & 0.48 \\
\hline $\operatorname{miR}-197$ & 0.62 \\
\hline miR-652 & 0.66 \\
\hline \multicolumn{2}{|c|}{ Up-regulated by E2F3 } \\
\hline$m i R-483-5 p$ & 7.73 \\
\hline$m i R-494$ & 3.18 \\
\hline$m i R-135 a^{*}$ & 2.07 \\
\hline
\end{tabular}

Table I. Continued.

\begin{tabular}{|c|c|}
\hline & Ratio \\
\hline$m i R-222$ & 1.92 \\
\hline$m i R-345$ & 1.89 \\
\hline$m i R-574-5 p$ & 1.59 \\
\hline \multicolumn{2}{|c|}{ Down-regulated by E2F3 } \\
\hline$m i R-15 b$ & 0.61 \\
\hline$m i R-183$ & 0.62 \\
\hline$m i R-10 a$ & 0.63 \\
\hline let-7d & 0.64 \\
\hline let-7e & 0.66 \\
\hline \multicolumn{2}{|c|}{ Up-regulated by E2F4 } \\
\hline None & - \\
\hline \multicolumn{2}{|c|}{ Down-regulated by E2F4 } \\
\hline$m i R-139-3 p$ & 0.64 \\
\hline \multicolumn{2}{|c|}{ Up-regulated by E2F5 } \\
\hline None & - \\
\hline \multicolumn{2}{|c|}{ Down-regulated by E2F5 } \\
\hline$m i R-139-3 p$ & 0.44 \\
\hline$m i R-370$ & 0.46 \\
\hline $\operatorname{miR}-149$ & 0.55 \\
\hline$m i R-654-5 p$ & 0.59 \\
\hline$m i R-892 b$ & 0.63 \\
\hline$m i R-30 c-1^{*}$ & 0.63 \\
\hline$m i R-105$ & 0.65 \\
\hline$m i R-345$ & 0.66 \\
\hline \multicolumn{2}{|c|}{ Up-regulated by E2F6 } \\
\hline miR-494 & 2.03 \\
\hline$m i R-513 a-5 p$ & 1.78 \\
\hline $\operatorname{miR}-513 c$ & 1.71 \\
\hline$m i R-513 b$ & 1.67 \\
\hline$m i R-1224-5 p$ & 1.62 \\
\hline \multicolumn{2}{|c|}{ Down-regulated by E2F6 } \\
\hline$m i R-629$ & 0.52 \\
\hline$m i R-139-3 p$ & 0.52 \\
\hline$m i R-105$ & 0.56 \\
\hline$m i R-370$ & 0.56 \\
\hline$m i R-345$ & 0.58 \\
\hline
\end{tabular}

The $m i R-483-5 p$ is localized to chromosome $11 \mathrm{p} 15.5$ within the intron of insulin-like growth factor 2 (IGF2, alias somatomedin A), whereas $m i R-494$ and $m i R-345$ are localized to an intergenic region. The orientation of transcription between miR-483-5p and IGF2 is the same. We tested whether the expressions of $m i R-483-5 p$ and $I G F 2$ were coordinated. Reverse transcription (RT)-PCR analysis revealed that the overexpression of E2F1 in A549 cells resulted in the upregulation of IGF2 mRNA (data not shown).

To ascertain the reproducibility of the miRNA expression profile obtained by the miRNA microarray analysis, we examined their expression levels by using a TaqMan real- 
Table II. Up- and down-regulation of miRNAs by HRAS, c-Jun and E2F1 E2F6 in HeLa cells.

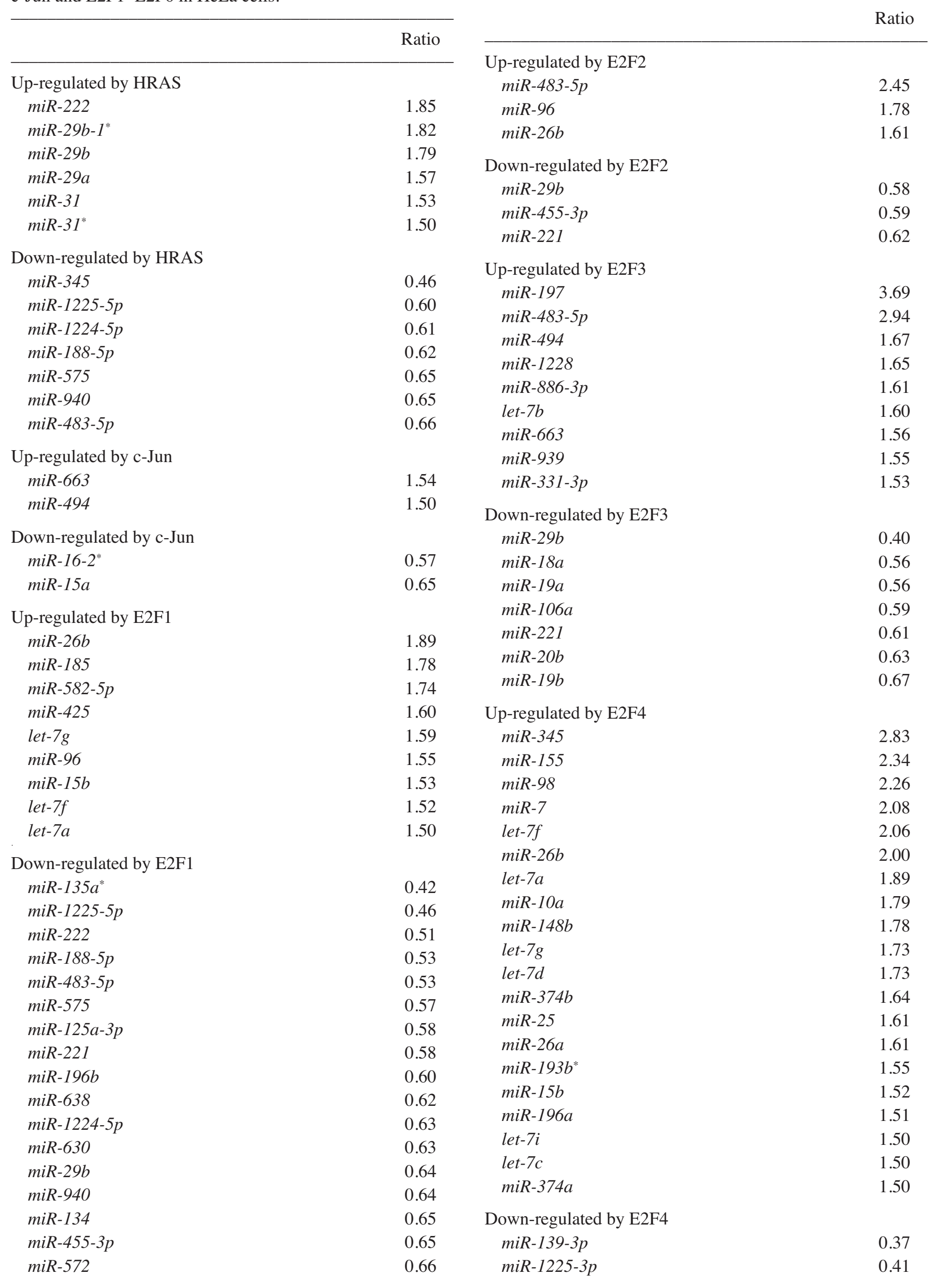


Table II. Continued.

\begin{tabular}{|c|c|c|c|}
\hline & Ratio & & Ratio \\
\hline $\operatorname{miR}-1228$ & 0.43 & $m i R-654-5 p$ & 0.40 \\
\hline$m i R-654-5 p$ & 0.44 & $m i R-370$ & 0.44 \\
\hline$m i R-760$ & 0.46 & $m i R-1225-3 p$ & 0.44 \\
\hline$m i R-636$ & 0.48 & $m i R-892 b$ & 0.49 \\
\hline$m i R-1238$ & 0.48 & $m i R-1228$ & 0.51 \\
\hline$m i R-296-5 p$ & 0.48 & $m i R-1238$ & 0.52 \\
\hline$m i R-892 b$ & 0.52 & $m i R-513 b$ & 0.52 \\
\hline$m i R-671-5 p$ & 0.53 & $m i R-636$ & 0.53 \\
\hline$m i R-886-3 p$ & 0.53 & $m i R-886-3 p$ & 0.53 \\
\hline$m i R-1234$ & 0.54 & $m i R-1234$ & 0.53 \\
\hline$m i R-501-5 p$ & 0.55 & $m i R-513 a-5 p$ & 0.55 \\
\hline$m i R-940$ & 0.57 & $m i R-494$ & 0.56 \\
\hline$m i R-638$ & 0.57 & $m i R-671-5 p$ & 0.56 \\
\hline$m i R-513 a-5 p$ & 0.58 & $m i R-500$ & 0.60 \\
\hline$m i R-877^{*}$ & 0.58 & $m i R-187^{*}$ & 0.60 \\
\hline$m i R-574-3 p$ & 0.58 & $m i R-877^{*}$ & 0.61 \\
\hline$m i R-1229$ & 0.59 & $m i R-1229$ & 0.61 \\
\hline$m i R-513 b$ & 0.60 & $m i R-125 a-3 p$ & 0.63 \\
\hline $\operatorname{miR}-370$ & 0.60 & $m i R-149^{*}$ & 0.64 \\
\hline$m i R-494$ & 0.61 & $m i R-16-2^{*}$ & 0.64 \\
\hline miR-630 & 0.62 & $m i R-21^{*}$ & 0.64 \\
\hline$m i R-583$ & 0.62 & $\operatorname{miR}-638$ & 0.65 \\
\hline$m i R-939$ & 0.62 & $m i R-940$ & 0.67 \\
\hline $\operatorname{miR}-572$ & 0.62 & Up-regulated by E2F6 & \\
\hline$m i R-373^{*}$ & 0.63 & $m i R-345$ & 2.80 \\
\hline$m i R-125 a-3 p$ & 0.64 & $m i R-98$ & 2.01 \\
\hline$m i R-21^{*}$ & 0.64 & let-7f & 1.85 \\
\hline $\operatorname{miR}-663$ & 0.65 & $m i R-148 b$ & 1.83 \\
\hline$m i R-874$ & 0.66 & let-7a & 1.79 \\
\hline Up-regulated by E2F5 & & $m i R-10 a$ & 1.78 \\
\hline$m i R-345$ & 3.25 & $m i R-26 b$ & 1.75 \\
\hline $\operatorname{miR}-98$ & 2.19 & $m i R-7$ & 1.61 \\
\hline$m i R-7$ & 2.03 & let-7d & 1.61 \\
\hline let-7f & 1.96 & let $-7 g$ & 1.60 \\
\hline $\operatorname{miR}-155$ & 1.92 & let $-7 c$ & 1.57 \\
\hline$m i R-26 b$ & 1.87 & $m i R-155$ & 1.56 \\
\hline let-7a & 1.82 & let-7e & 1.54 \\
\hline $\operatorname{miR}-148 b$ & 1.81 & $\operatorname{miR}-196 a$ & 1.54 \\
\hline let $-7 g$ & 1.78 & let- $7 b$ & 1.51 \\
\hline let-7d & 1.67 & $m i R-25$ & 1.50 \\
\hline$m i R-10 a$ & 1.67 & Down-regulated by E2F6 & \\
\hline$m i R-25$ & 1.62 & miR-139-3p & 0.28 \\
\hline$m i R-520 b$ & 1.60 & $m i R-1225-3 p$ & 0.44 \\
\hline let $-7 c$ & 1.56 & $m i R-296-5 p$ & 0.45 \\
\hline$m i R-196 a$ & 1.53 & $m i R-636$ & 0.48 \\
\hline $\operatorname{miR}-224$ & 1.53 & $m i R-654-5 p$ & 0.49 \\
\hline $\operatorname{miR}-374 b$ & 1.51 & miR-1228 & 0.50 \\
\hline let-7i & 1.51 & miR-501-5p & 0.52 \\
\hline let-7e & 1.50 & $\operatorname{miR}-1229$ & 0.53 \\
\hline Down-regulated by E2F5 & & $m i R-671-5 p$ & 0.54 \\
\hline$m i R-139-3 p$ & 0.36 & $\operatorname{miR}-187^{*}$ & 0.54 \\
\hline
\end{tabular}

Table II. Continued.

2.80

1.83

1.79

54

54

51

50

.28

0.44

0.45

0.48

0.49

0.50

.52

.53

0.54 
Table II. Continued.

\begin{tabular}{ll}
\hline & Ratio \\
\hline miR-1234 & 0.55 \\
miR-638 & 0.56 \\
miR-892b & 0.56 \\
miR-500 & 0.56 \\
miR-370 & 0.56 \\
miR-149* & 0.57 \\
miR-940 & 0.57 \\
miR-886-3p & 0.57 \\
miR-630 & 0.59 \\
miR- -87238 & 0.59 \\
miR-125a-3p & 0.61 \\
miR-424* & 0.61 \\
miR-623 & 0.61 \\
miR-572 & 0.62 \\
miR-21* & 0.63 \\
miR-939 & 0.64 \\
miR-513a-5p & 0.67 \\
\hline
\end{tabular}

time RT-PCR. As a representative transcription factor, we transfected c-Jun into A549 cells, and $48 \mathrm{~h}$ after transfection, quantitative expression level for $m i R-494$ normalized to $R N U 6 B$ was determined. The TaqMan miRNA assay showed that $m i R-494$ was up-regulated in c-Jun overexpressed A549 cells by 4 -fold compared to pcDNA3 control vector transfected cells (Fig. 2D).

Silencing effect of miR-483-5p and $m i R-494$. The miRNAmediated suppression of translation from target mRNA is known to occur through a complementarity to the 3'UTR of the target mRNA (38). We validated the effects of $m i R-483-5 p$ and $m i R-494$ on the luciferase gene reporter, which possesses the miRNA target sequence in the 3'UTR. For this purpose, synthesized mature miRNAs were introduced into A549 cells, and $24 \mathrm{~h}$ thereafter, luciferase reporter was transfected. Both $m i R-483-5 p$ and $m i R-494$ successfully down-regulated their own target sequence bearing the luciferase reporter, compared with control RNA (Fig. 3A and B). Next we tested whether endogenous $m i R-483-5 p$ and $m i R-494$ could suppress the luciferase gene reporter. For this, we co-transfected E2F1 expression vector and luciferase gene reporter, which possesses the $m i R-483-5 p$ or $m i R-494$ target sequence in the 3'UTR, in A549 cells. Based on a miRNA microarray results described above, E2F1 up-regulated the expression level for $m i R-483-5 p$ and $m i R-494$. Nevertheless, after $72 \mathrm{~h}$ of transfection, E2F1 failed to suppress the luciferase gene reporter activity (Fig. 3C and D).

Signaling pathways regulated by selected miRNAs. We next searched for signaling pathways that can be regulated by the miRNAs identified above. For this purpose, we introduced synthesized mature miRNA ( $m i R-483-5 p, m i R-494$ and $m i R$ - 139-3p inhibitor) into A549 cells. The reporters contained the responsive elements for 14 different transcription factors/ signal transduction pathways [ISRE (interferon-stimulated response element) was tested only for $m i R$-494] upstream of the luciferase gene. Among the elements that were tested, only the activity of the GAS (interferon $\gamma$ activation site) reporter was increased 2 -fold by $m i R-494$, compared with that of the control (Fig. 3E), suggesting that miR-494 might target the inhibitor(s) of JAK (janus kinases)/STAT (signal transducers and activators of transcription) signaling upstream of the GAS element. The miR-483-5p and $m i R-139-3 p$ inhibitor showed no effect on the reporters that were tested (data not shown).

\section{Discussion}

How miRNAs are deregulated through signal transduction pathways during carcinogenesis is a major concern (39). Here, we investigated the mammalian cell proliferation control network, consisting of the transcriptional regulators HRAS, c-Jun and E2F1 E2F6, to seek an answer to the above question. Tiny, mature miRNAs can negatively regulate specific target mRNAs by translational inhibition or mRNA degradation (7). The expression levels of miRNAs are well correlated with the etiology of carcinogenesis $(8,9)$. In this study, we revealed that transcriptional regulators uniquely control a characteristic subset of miRNA in a cell-specific manner. Among them, we noted that $m i R-483-5 p, m i R-494$, $m i R-345, m i R-139-3 p$ and $m i R-370$ might serve as potential diagnostic markers of carcinogenesis. So far, several reports on these miRNAs are available as discussed in more detail below.

An expression profiling-based analysis revealed that $m i R-483-5 p$ is up-regulated in malignant adrenocortical tumors, compared with in benign ones, indicating that the upregulation of $m i R-483-5 p$ might be associated with a poorer cancer-specific survival (40). $m i R-494$ was first reported as part of a miRNA expression profile for retinoblastoma, belonging to a cluster of highly expressed miRNAs (41). Recently, in a cultured primary bronchial epithelial cell system exposed to benzo[a]pyrene, miR-494 expression was upregulated in parallel with the down-regulated expression of CDK6 (42). miR-494 also decreased PTEN (phosphatase and tensin homolog) protein and reportedly functions as an oncogene in primary bronchial epithelial cell carcinogenesis (43). Based on the elevated expression of miR-494 in pRbinactivated cells, it is highly possible that deregulated E2F might activate $m i R-494$ expression. This notion agrees well with our present results. PTEN and CDK6 are in silico targets of $m i R-494$, as easily predicted by TargetScan 5.0 (http://www. targetscan.org/). One reason explaining why $m i R-494$ only activated the GAS reporter in the present study is that while PTEN might indeed be a direct target of $m i R-494$, it failed to modulate any of the signaling pathways examined in the present assay. Probably, the down-regulation of CDK6 induced by $m i R-494$ in A549 cells was too small to modulate the activity of the reporters. miRNAs are known to have multiple target genes (44). Therefore, it is rather surprising that $m i R-494$ only affected the signaling pathway represented by the GAS element (45). Intriguingly, miR-494 did not have any effect 
A

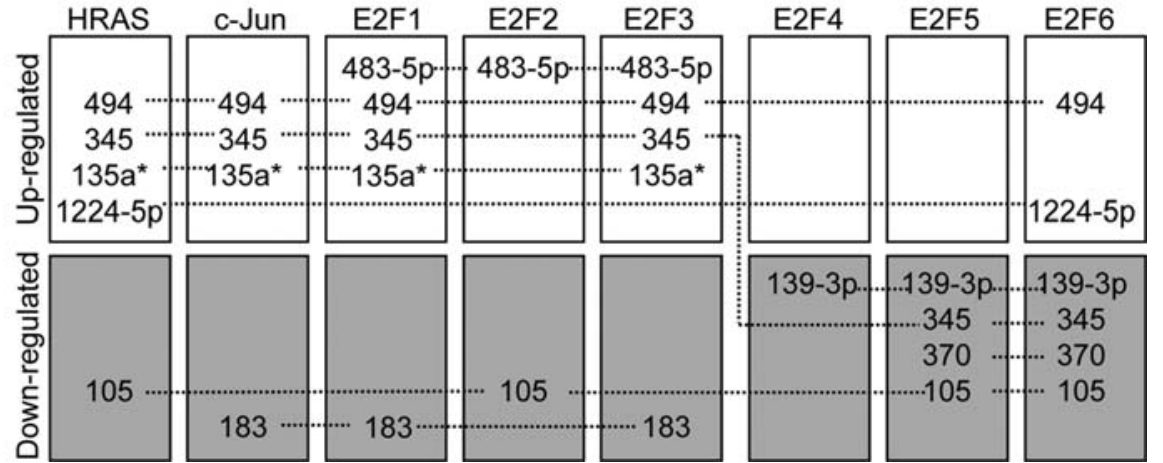

B

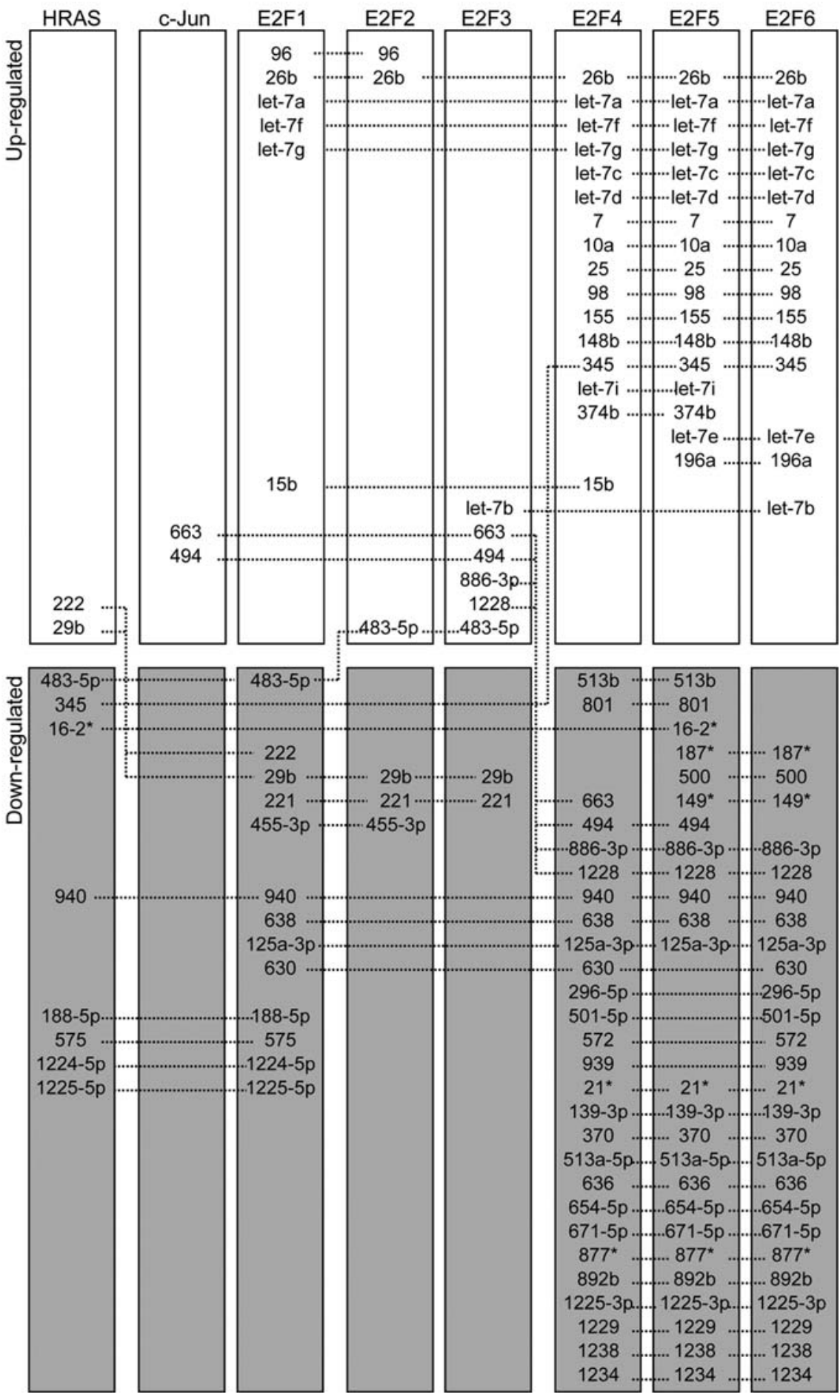

Figure 2. A-C. Representative miRNAs regulated by transcriptional regulators. 
C

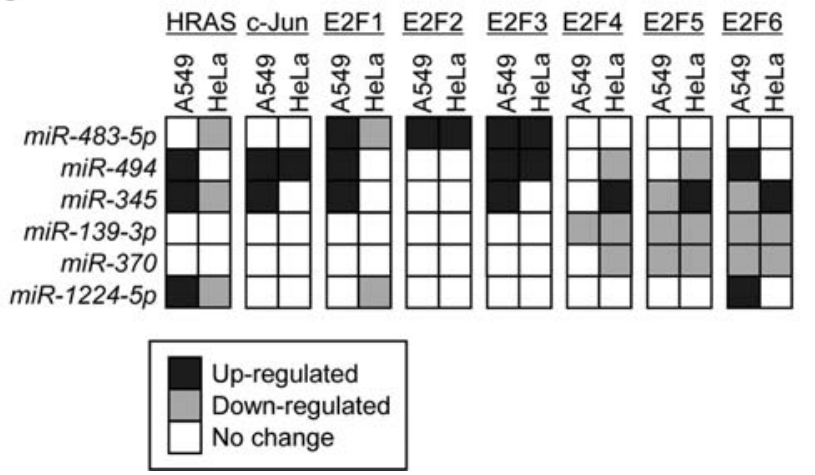

D

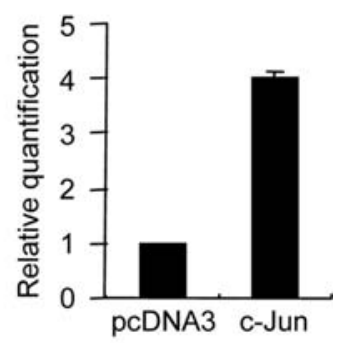

Figure 2. Representative miRNAs regulated by transcriptional regulators. Commonly up- and down-regulated miRNAs by at least two different transcriptional regulators in A549 (A) and HeLa (B) cells are connected with a dotted line. (C) miRNAs commonly regulated in A549 and HeLa cells. (D) TaqMan miRNA assay using a real-time-PCR for miR-494 in c-Jun overexpressed A549 cells. The value of the cells transfected with pcDNA3 was designated as 1 . The bar indicates RQ harboring RQ Max and RQ Min.

\section{A}

B pGL3-Promoter-483-5p

C

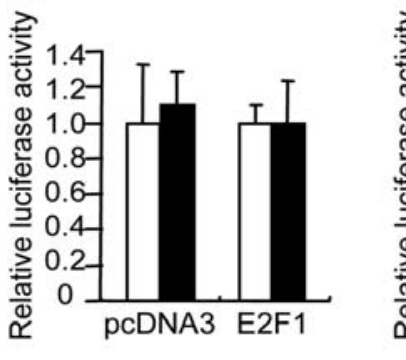

\section{$\square$ pGL3-Promoter pGL3-Promoter-483-5p}

$\mathrm{E}$

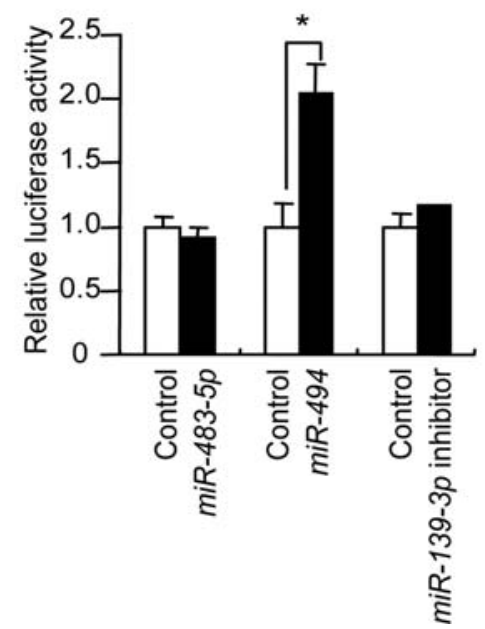

Figure 3. Luciferase reporter activity regulated by miRNAs in A549 cells. Synthetic mature miRNAs $m i R-483-5 p$ (A) and $m i R-494$ (B) were tested for luciferase gene reporter, which possesses the $m i R-483-5 p$ or $m i R-494$ target sequence in the 3'UTR. Relative luciferase activity was shown as the value obtained when control RNA co-transfection with pGL3-Promoter-based reporters were defined as 1 . White and black bars indicate pGL3-Promoter and pGL3-Promoter-483-5p (or pGL3-Promoter-494), respectively. Values are expressed as the means $\pm \mathrm{SD}(\mathrm{n}=3) .{ }^{*} \mathrm{P}<0.05$, using a one-tailed Student's t-test. Co-transfection of E2F1 expression vector and luciferase gene reporter, which possesses the $m i R-483-5 p$ (C) or $m i R-494$ (D) target sequence in the 3'UTR. After $72 \mathrm{~h}$ of transfection, the luciferase gene reporter activity was measured. Relative luciferase activity was shown as the value obtained when pGL3-Promoter reporter co-transfection with pcDNA3 or E2F1 was defined as 1, respectively. White and black bars indicate pGL3-Promoter and pGL3-Promoter-483-5p (or pGL3-Promoter-494), respectively. Values are expressed as the means $\pm \mathrm{SD}(\mathrm{n}=3)$. (E) Comparison of miRNA effects on a GAS responsive element-bearing luciferase reporter. $m i R-483-5 p$, $m i R-494$ or $m i R-139-3 p$ inhibitor was transfected with the reporter plasmid. Relative luciferase activity was shown as the value obtained when control RNA co-transfection with pGAS-TA-Luc was defined as 1. Before this, adjusted data was obtained by dividing luciferase activity of pGAS-TA-Luc co-transfected with control RNA or miRNA by that of pTA-Luc cotransfected with control RNA or miRNA, respectively. White and black bars indicate pTA-Luc and pGAS-TA-Luc, respectively. Values are expressed as the means $\pm \mathrm{SD}(\mathrm{n}=3) .{ }^{*} \mathrm{P}<0.05$ (compared with control RNA-transfected cells), using a two-tailed Student's t-test.

on the ISRE, indicating that miR-494 affected a signaling molecule specifically involved in GAS but not in ISRE signaling. p38 MAP kinase is known to be essential for gene transcription via the GAS element (46). Indeed, $m i R-494$ is up-regulated by HRAS in A549 cells. A more detailed analysis of how HRAS, c-Jun and E2Fs-activated miR-494 is involved in the regulation of cytokine-induced gene expression should be defined in the context of immune-related cell system, especially with regard to the JAK/STAT signaling pathways (47). Consequently, the current approach employing reporters with various elements for signaling pathways might not be sufficient to detect down-regulated targets.

miRNA profiling using a miRNA microarray revealed that $m i R-345$ was highly expressed in malignant mesothelioma, compared with normal mesothelium (48). Expression profiling revealed that an increase in $m i R-345$ expression was consistently observed during the progression of oral leuko- 
plakia lesions into oral squamous cell carcinoma (49). Interestingly, $m i R-345$ was also found to be the most significantly dysregulated miRNA in cisplatin-resistant MCF-7 human breast adenocarcinoma cells and to target the human multidrug resistance-associated protein 1 (MRP1) (50).

Based on evidence from previous reports, $m i R-483-5 p$, $m i R-494$ and $m i R-345$ can all be considered as oncogenes. Our present results also support this notion. A comparison between A549 (p53 wild-type) and HeLa [with p53 silenced by HPV (human papillomavirus) genome integration] cells revealed that the miRNA expression patterns were not necessarily conserved, but were partially matched. These results suggest that the p53 status might be responsible for the miRNA signature regulated by transcription factors such as E2F and c-Jun as well as c-Myc. Needless to say, functional studies are needed to explain how these commonly regulated miRNAs can control cellular phenotypes in certain cells. Among the reported E2F1-regulated miRNAs, miR-17-92 cluster (miR-17-5p, miR-17-3p, miR-18a, miR-19a, miR-19b-1, $m i R-20 a$ and $m i R-92-1)$ were not detected in the present study $(22,23)$ except for down-regulation of $m i R-18 a$ and $m i R-19 a$ by E2F3 in HeLa cells. This discrepancy probably be due to the differences of cell types tested and expression systems for E2F1 (22,23). For example, E2F1-inducible Saos-2 cell line where E2F1 is fused to the estrogen receptor-binding domain was used to identify $m i R-449 a / b$ as novel E2F1-inducible targets (19). These miRNAs were not detected in the present study. In contrast, in E2F1/3-knockout cells, miRNA clusters including let-7a-d and let-7i were identified as direct targets of E2F1 and E2F3 (51). In the present study, let-7a, let-7f and $l e t-7 g$ were up-regulated by E2F1 and E2F4 6 in HeLa cells. In addition, let-7b was up-regulated by E2F3 and E2F6, and $l e t-7 c$ and $l e t-7 d$ were up-regulated by $\mathrm{E} 2 \mathrm{~F} 4 \sim 6$, and let-7e was up-regulated by E2F5 and E2F6, and let-7i was upregulated by E2F4 and E2F5 in HeLa cells. Conversely, let-7d and let-7e were down-regulated by E2F3 in A549 cells. As well $m i R-17-92$ cluster, $m i R-106 b$ - 25 cluster has been shown to be regulated by E2F1 (18). Notably, miR-25 was solely up-regulated by E2F4 6 in HeLa cells but not in A549 cells. Collectively, comprehensive analysis of cell type-specific miRNAs expression regulated by various transcription factors enables us to select unique and common miRNAs that can be utilized as disease specific biomarkers for prognosis, diagnosis and therapeutics.

Direct introduction of synthetic mature miRNAs clearly suppressed the activities of luciferase gene reporters, which possesses miRNAs responsive sequences in the 3'UTR of luciferase gene. Contrary to this, ectopic expression of E2F1 failed to modulate the activities of these luciferase gene reporters. This can be explained by the fact that the amounts of synthetic mature miRNAs are overwhelming when compared to those of endogenous miRNAs induced by E2F1. Alternatively, within $72 \mathrm{~h}$ of assay interval, secondary effects of E2F1 may be occurred. Indeed, E2F1 has been shown to be involved in the complex gene network (28).

In conclusion, we identified $m i R-483-5 p, m i R-494$, $m i R-345, m i R-139-3 p$ and $m i R-370$ as comprising a unique subset of miRNAs located downstream of pivotal transcription factors in A549 and HeLa cells. We believe that the present miRNA profiling results contribute to a unique aspect of the miRNA regulation that is involved in the complex gene regulatory network of cancerous cells.

\section{Acknowledgements}

This study was supported in part by Grant from the Vehicle Racing Commemorative Foundation and Research Project Grant by Institute of Science and Technology Meiji University. We thank the members of the Yoshida laboratory for their technical assistance.

\section{References}

1. Roberts PJ and Der CJ: Targeting the Raf-MEK-ERK mitogenactivated protein kinase cascade for the treatment of cancer. Oncogene 26: 3291-3310, 2007.

2. Young A, Lyons J, Miller AL, Phan VT, Alarcón IR and McCormick F: Ras signaling and therapies. Adv Cancer Res 102: 1-17, 2009.

3. Brown CJ, Lain S, Verma CS, Fersht AR and Lane DP: Awakening guardian angels: drugging the p53 pathway. Nat Rev Cancer 9: 862-873, 2009.

4. Brooks TA and Hurley LH: The role of supercoiling in transcriptional control of MYC and its importance in molecular therapeutics. Nat Rev Cancer 9: 849-861, 2009.

5. Verde P, Casalino L, Talotta F, Yaniv M and Weitzman JB: Deciphering AP-1 function in tumorigenesis: fra-ternizing on target promoters. Cell Cycle 6: 2633-2639, 2007.

6. Seville LL, Shah N, Westwell AD and Chan WC: Modulation of $\mathrm{pRB} / \mathrm{E} 2 \mathrm{~F}$ functions in the regulation of cell cycle and in cancer. Curr Cancer Drug Targets 5: 159-170, 2005.

7. Garzon R, Calin GA and Croce CM: MicroRNAs in cancer. Annu Rev Med 60: 167-179, 2009.

8. Zhang B, Pan X, Cobb GP and Anderson TA: microRNAs as oncogenes and tumor suppressors. Dev Biol 302: 1-12, 2007.

9. Stefani G: Roles of microRNAs and their targets in cancer. Expert Opin Biol Ther 7: 1833-1840, 2007

10. Johnson CD, Esquela-Kerscher A, Stefani G, et al: The let-7 microRNA represses cell proliferation pathways in human cells. Cancer Res 67: 7713-7722, 2007.

11. Johnson SM, Grosshans H, Shingara J, et al: RAS is regulated by the let-7 microRNA family. Cell 120: 635-647, 2005.

12. Sachdeva M, Zhu S, Wu F, et al: p53 represses c-Myc through induction of the tumor suppressor miR-145. Proc Natl Acad Sci USA 106: 3207-3212, 2009.

13. Hermeking H: p53 enters the microRNA world. Cancer Cell 12: 414-418, 2007.

14. He L, He X, Lowe SW and Hannon GJ: microRNAs join the p53 network - another piece in the tumour-suppression puzzle. Nat Rev Cancer 7: 819-822, 2007

15. He L, He X, Lim LP, et al: A microRNA component of the p53 tumour suppressor network. Nature 447: 1130-1134, 2007.

16. Corney DC, Flesken-Nikitin A, Godwin AK, Wang W and Nikitin AY: MicroRNA-34b and MicroRNA-34c are targets of p53 and cooperate in control of cell proliferation and adhesionindependent growth. Cancer Res 67: 8433-8438, 2007.

17. Tazawa H, Tsuchiya N, Izumiya $M$ and Nakagama H: Tumorsuppressive miR-34a induces senescence-like growth arrest through modulation of the E2F pathway in human colon cancer cells. Proc Natl Acad Sci USA 104: 15472-15477, 2007.

18. Brosh R, Shalgi R, Liran A, et al: p53-Repressed miRNAs are involved with E2F in a feed-forward loop promoting proliferation. Mol Syst Biol 4: 229, 2008.

19. Yang X, Feng M, Jiang X, et al: miR-449a and miR-449b are direct transcriptional targets of E2F1 and negatively regulate pRb-E2F1 activity through a feedback loop by targeting CDK6 and CDC25A. Genes Dev 23: 2388-2393, 2009.

20. O'Donnell KA, Wentzel EA, Zeller KI, Dang CV and Mendell JT: c-Myc-regulated microRNAs modulate E2F1 expression. Nature 435: 839-843, 2005.

21. He L, Thomson JM, Hemann MT, et al: A microRNA polycistron as a potential human oncogene. Nature 435: 828-833, 2005.

22. Sylvestre Y, De Guire V, Querido E, et al: An E2F/miR-20a autoregulatory feedback loop. J Biol Chem 282: 2135-2143, 2007. 
23. Woods K, Thomson JM and Hammond SM: Direct regulation of an oncogenic micro-RNA cluster by E2F transcription factors. J Biol Chem 282: 2130-2134, 2007.

24. Yan HL, Xue G, Mei Q, et al: Repression of the miR-17-92 cluster by p53 has an important function in hypoxia-induced apoptosis. EMBO J 28: 2719-2732, 2009.

25. Aguda BD, Kim Y, Piper-Hunter MG, Friedman A and Marsh CB: MicroRNA regulation of a cancer network: consequences of the feedback loops involving miR-17-92, E2F, and Myc. Proc Natl Acad Sci USA 105: 19678-19683, 2008.

26. Lotterman CD, Kent OA and Mendell JT: Functional integration of microRNAs into oncogenic and tumor suppressor pathways. Cell Cycle 7: 2493-2499, 2008

27. Coller HA, Forman JJ and Legesse-Miller A: 'Myc'ed messages' myc induces transcription of E2F1 while inhibiting its translation via a microRNA polycistron. PLoS Genet 3: e146, 2007.

28. Polager S and Ginsberg D: p53 and E2f: partners in life and death. Nat Rev Cancer 9: 738-748, 2009.

29. Volinia S, Calin GA, Liu CG, et al: A microRNA expression signature of human solid tumors defines cancer gene targets. Proc Natl Acad Sci USA 103: 2257-2261, 2006.

30. Lee YS and Dutta A: MicroRNAs in cancer. Annu Rev Pathol 4: 199-227, 2009.

31. Xi Y, Edwards JR and Ju J: Investigation of miRNA biology by bioinformatic tools and impact of miRNAs in colorectal cancerregulatory relationship of c-Myc and p53 with miRNAs. Cancer Inform 3: 245-253, 2007.

32. Yin Q, Wang X, McBride J, Fewell C and Flemington E: B-cell receptor activation induces $\mathrm{BIC} / \mathrm{miR}-155$ expression through conserved AP-1 element. J Biol Chem 283: 2654-2662, 2008.

33. Sato K, Kusama Y, Tategu M and Yoshida K: FBXL16 is novel E2F1-regulated gene commonly upregulated in p16INK4Aand p14ARF-silenced HeLa cells. Int J Oncol 36: 479-490, 2010

34. Tategu M, Nakagawa H, Hayashi R and Yoshida K: Transcriptional co-factor CDCA4 participates in the regulation of JUN oncogene expression. Biochimie 90: 1515-1522, 2008.

35. Yoshida K and Inoue I: Regulation of Geminin and Cdt1 expression by E2F transcription factors. Oncogene 23: 3802-3812, 2004.

36. Griffiths-Jones S, Saini HK, van Dongen S and Enright AJ miRBase: tools for microRNA genomics. Nucleic Acids Res 36: D154-D158, 2008.

37. Barbacid M: ras genes. Annu Rev Biochem 56: 779-827, 1987.

38. Lai EC: Micro RNAs are complementary to 3'UTR sequence motifs that mediate negative post-transcriptional regulation. Nat Genet 30: 363-364, 2002.
39. Shi XB, Tepper CG and DeVere White RW: Cancerous miRNAs and their regulation. Cell Cycle 7: 1529-1538, 2008.

40. Soon PS, Tacon LJ, Gill AJ, et al: miR-195 and miR-483-5p identified as predictors of poor prognosis in adrenocortical cancer. Clin Cancer Res 15: 7684-7692, 2009.

41. Zhao JJ, Yang J, Lin J, et al: Identification of miRNAs associated with tumorigenesis of retinoblastoma by miRNA microarray analysis. Childs Nerv Syst 25: 13-20, 2009.

42. Duan H, Jiang Y, Zhang $\mathrm{H}$ and Wu Y: MiR-320 and miR-494 affect cell cycles of primary murine bronchial epithelial cells exposed to benzo[a]pyrene. Toxicol In Vitro 23: 53-59, 2009.

43. Liu L, Jiang Y, Zhang H, Greenlee AR and Han Z: Overexpressed miR-494 down-regulates PTEN gene expression in cells transformed by anti-benzo(a)pyrene-trans-7,8-dihydrodiol-9,10epoxide. Life Sci 86: 192-198, 2010.

44. Flynt AS and Lai EC: Biological principles of microRNAmediated regulation: shared themes amid diversity. Nat Rev Genet 9: 831-842, 2008

45. Decker T, Kovarik P and Meinke A: GAS elements: a few nucleotides with a major impact on cytokine-induced gene expression. J Interferon Cytokine Res 17: 121-134, 1997.

46. Platanias LC: The p38 mitogen-activated protein kinase pathway and its role in interferon signaling. Pharmacol Ther 98: 129-142, 2003.

47. Darnell JEJ, Kerr IM and Stark GR: Jak-STAT pathways and transcriptional activation in response to IFNs and other extracellular signaling proteins. Science 264: 1415-1421, 1994.

48. Guled M, Lahti L, Lindholm PM, et al: CDKN2A, NF2, and JUN are dysregulated among other genes by miRNAs in malignant mesothelioma - a miRNA microarray analysis. Genes Chromosomes Cancer 48: 615-623, 2009.

49. Cervigne NK, Reis PP, Machado J, et al: Identification of a microRNA signature associated with progression of leukoplakia to oral carcinoma. Hum Mol Genet 18: 4818-4829, 2009.

50. Pogribny IP, Filkowski JN, Tryndyak VP, Golubov A, Shpyleva SI and Kovalchuk O: Alterations of microRNAs and their targets are associated with acquired resistance of $\mathrm{MCF}-7$ breast cancer cells to cisplatin. Int J Cancer 127: 1785-1794, 2010.

51. Bueno MJ, Gómez de Cedrón M, Laresgoiti U, FernándezPiqueras J, Zubiaga A and Malumbres M: Multiple E2F-induced microRNAs prevent replicative stress in response to mitogenic signalling. Mol Cell Biol 30: 2983-2995, 2010. 